\title{
Discussion: Watford match day parking scheme
}

\section{A. Thomas}

Martin Roach, Metronet Rail BCV

I read Alison Thomas's paper with great interest-both as a member of the Transport journal's editorial panel, and as a resident within the area covered by the scheme. I can therefore speak from experience of the preparation and establishment of the scheme, and how it is now working in practice almost three years on. As a regular spectator of football and rugby at Vicarage Road Stadium, albeit as one fortunate enough to live within walking distance, I also have a degree of empathy with those who have to travel by car to reach the ground.

I would firstly concur with Ms Thomas's conclusion that the scheme has overall been a great success. As she states in paragraph 1.1, prior to the introduction of the scheme, residents felt trapped in their houses for fear of being unable to return during games, whereas now we can travel to and from home when we wish on match days. The Council must be complimented on the extensive consultation process that they went through prior to implementation of the scheme and being prepared to listen to suggestions for fine-tuning of the proposals. The main complaint that remained was the charge for the parking permits-people objected to having to pay for the 'privilege' of parking near their own homes. However, once the success of the scheme was demonstrated, it became clear that $£ 5$ per car per season was really quite a modest price to pay for the peace of mind brought about by knowing that a parking spot would be available on a match day.

The main ongoing problem persists when fixtures are rearranged in mid-season-either by the requirements of television companies if either Watford FC or Saracens RFC matches are chosen to be broadcast live (often with a change of date or kick-off time); or when games are rescheduled following earlier postponement arising from bad weather. Although the date/time of the 'next fixture' is posted on signs at the entrance to the match day parking zones, these are not always obvious to those living within the area. An elderly neighbour was caught out by this early on when he received a visit from his non-resident son one evening when such a rearranged fixture took place, who duly received a parking ticket for his trouble. The onus still falls on residents to acquaint themselves with these changes, although they are advertised in the local press and there is a 'fixture hotline' number to ring to check for changes.

Another problem referred to by Ms Thomas in her conclusion is that of untaxed and abandoned vehicles. Although not unique to West Watford, the numbers of these have been steadily growing during the three years that the scheme has been operating, slowly eroding the number of parking bays available. However, the Council has recently been tackling this issue with a degree of vigour, reducing the numbers of such vehicles considerably in recent months, so hopefully this problem will reduce as the 2004-2005 season beckons.

One matter does still puzzle me, however, which is not mentioned in Ms Thomas's paper. In the early 1980s a new rail platform, Watford Stadium Halt, was built on the Watford Junction to Croxley Green local (single track) line to serve the stadium on match days. This fell into disuse after a few years, but reinstating it would surely be another means of bringing people who currently come by car to the ground by train instead. Was this considered by Arup in their studies, or discounted because of the line's current 'mothballed' status?

\footnotetext{
Author's reply

I welcome the comments from Mr. Roach on the success of the scheme and its effectiveness. The problem of changes to fixture dates and times for the residents is acknowledged and there is an onus on them to be aware that these can change. Regarding your point on Watford Stadium Halt, this was not included in the study-the consultancy was commissioned only to undertake a match day parking scheme for the Council; however, the Council may have considered improvements to Watford Stadium Halt separately. Although such improvements may ease the parking situation, they would not be enough of an incentive on their own to stop supporters driving to the stadium and parking in the residential streets nearby.
} 